AMIR KARIMIPOUR

Ferdowsi University of Mashhad

amir.karimipour@ferdowsi.um.ac.ir

SHAHLA SHARIFI (corresponding author)

Ferdowsi University of Mashhad

sh-sharifi@um.ac.ir

\title{
AN EXPERIMENTAL STUDY ON DEICTIC VERBS AND THE CODING PATTERNS OF DEIXIS IN ILAMI KURDISH: A COMPARATIVE STUDY
}

Keywords: deictic verbs, venitive verbs, motion, functional space, IK

\begin{abstract}
Conducting a video-based experiment in English, Japanese and Thai, Matsumoto et al. (2017) report that deictic verbs are more frequently used when the motion is not just toward the speaker but also into his/her functional space (i.e. functional HERE of the speaker) defined by limits of interaction and visibility as well as when the motion is accompanied by an interactional behaviour of the Figure such as greeting the speaker. They claim that directional venitive prepositional phrases (henceforth PPs) like toward me do not exhibit this feature, though. This paper aims to reevaluate these proposals (Matsumoto et al. 2017) in Ilami Kurdish (henceforth IK), thereby figuring out whether the functional nature of deictic verbs observed in the three studied languages is also attested in this dialect. In line with the findings reported by Matsumoto et al. (2017), results of this research reveal that the semantics of venitive verbs of motion in IK is spatial and functional at the same time. In other words, these verbs are more often used in the verbal descriptions of the IK participants, when the Figure shares a functional space with the speaker induced by limits of interaction and visibility, and also when he/she smiles at or greets the speaker. Importantly, results show that venitive PPs in IK can be functional in nature or add some functional meaning (in addition to their spatial meaning) to the verb, so that participants utilize venitive adpositions along with the venitive verb to add emphasis on the kind of motion (to be a venitive one) and express that the Figure would be "very close" to the speaker at the end of motion.
\end{abstract}


These findings suggest that although the functional nature of venitive verbs of motion seems to have a universal foundation, languages may also exhibit some nuances in the functional scope of these expressions.

\section{Introduction}

As Colasacco (2019: 71-72) explains:

Motion is an essential conceptual domain in both physical development and human cognition, and due to the frequency to which we refer to it in every-day communication, its expression is a basic factor of all languages. When we speak, our experiences of the world are filtered through our choice of words, and not only through the individual standpoint we take, but also through the wide set of options offered by the particular language we are speaking.

According to Talmy $(1975,1985,2000)$, the basic Motion event can be divided into separate components, including an object (the Figure) and its movement through a path (the Path) with respect to another reference object (the Ground). The following English sentence exemplifies different components of motion (Talmy 1975: 187):

(1) The bottle moved into the cove.

[Figure] [Motion] [Path] [Ground]

Some motion verbs, such as enter and exit, not only express the fact of Motion as seen in example (1), but also they include (part of) the Path information (e.g. into/out of an enclosure) in their lexical meaning. These verbs which have a special choice of the Path and the Ground are called Path-conflating motion verbs. As Talmy clarifies

[...] in languages that include it in their characteristic representation of Motion events, the Deictic component of Path typically has only the two member notions "toward the speaker" and "in a direction other than toward the speaker". Talmy (2000: 56)

Example (2) illustrates that the venitive verb come by default specifies the speaker as the Goal-ground in its lexical meaning.

(2) come

MOVE TOWARD a point which is the location of the speaker

[Motion] [Vector] [Conformation [Path ] [Ground]

] Nakazawa (2006: 285)

According to the formula represented above, Nakazawa (2006: 286) explains that

MOVE is an abstract verb which represents motion in a Motion event, and TOWARD is a component of the Path called Vector. The Vector expresses 'the basic types of arrival, traversal, and departure that a Figural schema can execute with respect to a Ground schema' (Talmy 2000: 53), 
and is represented in terms of abstract prepositions, called 'deep prepositions,' such as TOWARD and TO. It expresses the meaning of a preposition as well as the Path information conflated within the semantics of motion verbs. The Conformation is another component of the Path and specifies the spatial relation of the Path to the Ground.

Nakazawa (2009: 385-386) counts some factors which differentiate the venitive verb come and the andative verb go. She mentions that different kinds of paths of motion are encoded by the VPs (verb phrases) came to school and went to school. Taking into account these examples, she states came to school implies that the path of motion is bounded and the Figure necessarily arrives at school at the end of motion, however went to school which denotes an unbounded path does not. Considering the identical goal of motion in both cases, she explains that the entailment of arrival is determined by the verbs come and go themselves rather than the identical goals encoded along with them. Although the arrival concept, as an identifying factor, can be generalized to various languages, in the sense that "if the deictic motion verbs are specified for the entailment of arrival, then they must describe the motion directed to the deictic center, i.e. they must be coming verbs" (Nakazawa 2009: 385-386), cross-linguistic variations can also be observed in this respect. Nakazawa also points to another difference between come and go. She says that the universal goal of coming verbs is the location of the speaker, which is the deictic center for venitive motions; nonetheless, the location of addressee can be the goal of the motion in many languages such as English, Japanese, and Korean, but not in Chinese.

As can be seen above, previous studies have emphasized mainly the spatial utilization of deictic motion verbs in the world's languages. However, some other researchers propose new insights into the field of deictic motion verbs. For example, Oshima (2006a) proposes a "set-based" analysis of motion deixis. As he argues, deictic predicates refer to a contextually salient set of individuals or reference point(s) (RP) rather than a particular, single individual, or at most two (i.e. the speaker and the addressee). He then adds that since the meanings of deictic predicates involve reference to the contextually selected RP, we can conclude that they are contextsensitive. Treating the RP as a component of the context of utterance, he then presents the context tuple form as follows: <agent, (addressee,) time, place, RPi>. Accordingly, he claims that deictic predicates are contingent on the context of utterance, and so they can be considered as kinds of indexical expressions (as is the case for first person pronouns, for example).

Adopting the aforementioned set-based analysis of motion deixis, Oshima (2006b: 287) claims that "GO requires that no member of the RP be at the goal (of the described motion) while COME requires that some member thereof be at the goal”. According to him, the set-based analysis can be empirically efficient compared with the existing analyses which sometimes fail to explain some relevant issues. Beyond this, it enables us to identify the possible range of cross-linguistic variation in terms of two implicational hierarchies: 
(i) the person hierarchy for RP inclusion: 1 st $<2$ nd $<3$ rd, and (ii) the relevance hierarchy for deictic verbs: an RP member's location at the utterance time $<$ an RP member's location at the event time < an RP member's “home base”. Oshima (2006b: 287)

Beyond, he counts still another advantage of this proposed analysis which does not follow from analyses along the lines of Fillmore (1997). Based on his evaluation,

[...] the proposed analysis makes certain predictions as to possible felicity conditions for a given deictic verb (in a given language). It predicts, for example, that there can be no deictic verb which can be felicitously used if (i) the speaker is at the goal at the utterance time, (ii) the speaker is at the goal at the event time, or (iii) the addressee is at the goal at the utterance time. Oshima (2006b: 297)

Lindner (1983: 132; qtd. in Hampe 2000: 89) proposes that "UP paths have as either point of departure or as goal a region which we may call the region of interactive focus - the realm of shared experience, existence, action, function, conscious interaction and awareness". She (Lindner 1983: 129) clarifies that the up-path in the conceptual metaphor ACTIVE IS UP can denote (among other things) "the transition from a resting and motionless state to an active, operational, prototypically moving state". Based on Lindner's discovery, Hampe (2000: 89) explains that the up-path in the phrasal verb to face up to (sth.) implies a sense of action, and possibly even control, which the simple verb lacks. Beyond, Lindner (1983) highlights two other metaphoric links concerning the $u p$-path which motivate the use of the particle and preposition in this construction. First, the non-literal use of up in to face up to (sth.) can be regarded as a metaphorical extension of the literal meaning of up as in climb up to the top, go up to the third floor. Second, up can refer to reaching a goal, either in space or in some abstract domain, so it describes "a path from far to near" (Lindner 1983: 143). An example for a literal use of the notion of "increased proximity" in a verb-particle construction with up to is provided by to meet up, which codes 'coming together', in contrast with the simple verb to meet that merely denotes 'be together' (Lindner 1983: 144; qtd. in Hampe 2000: 91).

Another work which goes beyond the pure spatial meaning analysis of the deictic verbs is Matsumoto et al.'s (2017) research. On the basis of the results of a video-based production experiment in English, Japanese and Thai, they claim that venitive verbs are not only spatial, but also functional in nature. Put differently, deictic verbs such as come in English are used more often in the oral descriptions of the participants, when the motion is not just toward the speaker but also into his/her functional space defined by limits of interaction and visibility as well as when the motion is accompanied by an interactional behaviour of the Figure such as greeting or smiling at the speaker. Mastumoto et al. (2017) also claim that, on the contrary, directional venitive PPs like toward me do not exhibit this feature. In this paper, following Matsumoto et al. (2017), we attempt to answer the following questions concerning the functional nature of deictic verbs and coding patterns of deixis in IK: 
1. Linguistically, how deictic verbs are encoded in IK? Are deictic verbs encoded differently from other path components in this dialect?

2. Do the IK venitive verbs have functional meaning in addition to their spatial meaning?

3. To what extent is the frequency of the use of venitive verbs affected by functional factors and interactional behaviours of the Figure in IK?

Furthermore, the probable functional use of other venitive PPs/VPs in IK is arguably an important question to be addressed in this paper. The remainder of this paper is divided into four sections: 2 presents a sketch of the Kurdish language and particularly IK; the details on the encoding of deictic expressions are also laid out in this section. In section 3, information about participants, stimuli used, research procedure along with reports on the results obtained from the video-based experiment are provided. In section 4, there will be a discussion on the results. Finally, section 5 concludes.

\section{A sketch of the Kurdish language}

The Kurdish language has three main dialects: Northern Kurdish dialects, usually called Kurmanji, are spoken in northwest Iraq, Turkey, and Khurasan, in Iran (Gunter 2004: xxv-xxvi). Central Kurdish has two main dialects, namely Mukri, which is spoken in Iran, to the south of Lake Urmia, and Sorani, mainly used to the west of the Mukri region in the province of Erbil, Iraq. Southern Kurdish comprises different variants such as IK, Kermanshahi, Laki, Garusi and Sanjabi (see for example Oranskij 1979: 35-36; Asatrian 2009: 12).

IK, an under-resourced dialect, is one of the Kurdish varieties, which is spoken in Ilam, a small mountainous city in western Iran. This dialect has a rather rich inflectional system. For example, main passive construction, present perfect and pluperfect are all inflectionally formed in this dialect. By the way, IK like many Iranian varieties has lost its gender and case marking systems in nouns and pronouns. This can be considered a sharp distinction compared to the owning varieties of Kurmanji, which mark gender and/or different cases. By contrast, IK has pronominal affixes used to encode case relations, which are usually absent in the northern dialects of Kurdish (see Bynon 1979).

\subsection{The encoding of deictic expressions in IK}

Matsumoto et al. (2017) clarify that languages of the world can have different strategies to encode deictic expressions which do not necessarily accord to their general lexicalization patterns. Analyzing three languages (i.e. English, Japanese and Thai) of different typological class, they show that venitive expressions can be expressed in the main verb or through $\mathrm{VPs} / \mathrm{PPs}$, depending on the language and its tendencies. Based on Talmy's $(1991,2000)$ binary typology, English language is mainly 
a satellite-framed language encoding path through satellite outside the main verb. Japanese, on the other hand, is a verb-framed language, which conflates path with the verb. Using verb serialization, Thai is called an equipollently-framed language which cannot be classified according to Talmy's proposal concerning path coding typology (Zlatev, Yangklang 2004). Regardless of the lexicalization patterns of path coding position and the extent to which multiple verbs are used in these languages, ${ }^{1}$ deictic expressions can be encoded either in the main verb or through VPs/PPs. For example, English can encode deictic expression in the main verb as in (3a) or through adpositional phrases as in ( $3 b)$.

(3) English

a. A man came out of the room (verb)

b. A man walked toward me (PP)

Matsumoto et al. (2017: 99)

It appears that IK, which tends to satellite-framed languages in terms of encoding the path component outside the main verb, uses different strategies to encode deictic expression. The following examples illustrate how these concepts are expressed in this dialect.

(4) pejag-a dae (nam-a) mal-a hat-aw doer. Man-DEF from into-EZ house-DEF come.PST.3SG-towards out The man came out of the house.

(5) pejag-ce hat waraw mo.

Man-DEF come.PST.3sg toward me

The man came toward me.

(6) pejag-ce dae (nam-a) mal-a hat-aw doer u

Man-DEF from into-EZ house-DEF come.PST.3sG-towards out and

waraw mo hat.

toward me come.PST.3SG

The man came out of the house and came toward me.

(7) pejag-o hat.

Man-DEF come.PST.3sg

The man came.

As can be seen above, hatzn 'come' is the venitive verb, which can be used to encode the concept of "moving toward the speaker" in IK. The important fact about the use of this verb is that it can be used along with the source adpositional phrase,

Matsumoto (1996) explains that Japanese uses predicates which consist of more than one verb within a clause, and motion verbs can utilize their repertoire to a great extent (Matsumoto 2017). The verbs used for the encoding of motion events in Thai are also formed on the basis of the serial verb construction (Takahashi 2009a,b, 2017), which allow multiple verbs to co-occur (Thepkanjana 1986). On the contrary, English infrequently uses multiple verb constructions especially when the andative verb used is go (Morishita 2011; Matsumoto 2017). 
as in (4), the goal adpositional phrase as in (5), both or neither of them as in (6) and (7), respectively. It seems that there are nuances between these sentences and each of them can be used in different contexts. Analyzing the deictic verbs which have the source component along with them, we figure out that by explicating this component the place where the motion actually starts is focalized, and the deictic effect of the verb is somehow minimized. This is well inferred in example (4), in which doe maloc 'from the house' as the source of motion minimizes the deictic effect of the verb. Conversely, by explicating the goal information which already exists in the main deictic verb, hatan 'coming', the deictic effects of the verb enhances and on the other hand the goal-bias principle is also observed (see Karimipour, Rezai 2019 for a detailed discussion on the goal-over-source-predominance principle in IK). However, the encoding of the source and goal altogether seems to be infrequent and linguistically marked in IK. This low frequency refers to the general tendency of IK, which usually do not form complete-path (Karimipour, Rezai 2016). Accordingly, in example (6), alternatively, the deictic verb has been used twice in order to explicate the source and goal of motion in two separate predicates, even though in both cases the verb is the same. Moreover, the deictic verb can also be used when neither source nor goal is encoded. In these cases, naturally, the deictic meaning of the verb which is directly associated with the goal-ground (i.e. moving towards the speaker) is highlighted rather than the source which is not conflated with the deictic verb.

There are also some adpositional phrases through which the "moving towards the speaker" concept can be expressed. In examples (8) and (9), although the deictic verb haton 'coming' is present, pirijam 'in my direction' and nezikam 'near me' can highlight the intended deictic concept in the respective examples. On the contrary, in example (10), gam najon 'walking' along with weraw ma 'toward me' serves to encode the deictic motion in IK.

(8) pejag-a hat-aw piri-(ja)m.

Man-DEF come.PST.3SG-toward direction-me

The man came in my direction.

(9) pejag-e hat-aw nezik-am.

Man-DEF come.PST.3SG-toward near-me

The man came near me.

(10) zan-ce waraw mo gam na.

woman-DEF toward me pace put.PST.3SG

The woman walked toward me. 


\section{Experiment}

In this section, some explanations concerning participants, research procedure, and stimuli used are given.

\subsection{Participants}

Following Matsumoto et al. (2017), twelve IK participants (30-6o years old) were recruited for this experiment. We took several criteria into account for the recruitment of the participants. We opted to select only those speakers who: i) were native speakers of IK, ii) used IK in their daily conversations, and iii) have lived in the selected area, namely Ilam, their whole life (i.e. indigenous speakers). By doing this, we ensured that the elicited data actually reflect the features of the variety targeted for further assessments.

\subsection{Stimuli and research procedure}

As already stated, the experiment is carried out using a set of video-clips $(N=26)$ portraying different motions. The scenes used in this experiment are replicated based on the description and classification provided in Matsumoto et al. (2017), since the original video stimuli used in that research was not available for public use. The repetition of the experiment permits to see how different languages of the same or different typological classes encode the linguistic expressions being assessed. The 26 video clips used in this experiment portrayed different directions and were made on the basis of two functional factors: 1) whether the goal of motion is in the speaker's space (e.g. room) or outside that space; 2) whether the Figure smiled at and greeted the speaker or not. In addition to the 26 video-clips, four video-clips were also used as fillers. Following Matsumoto et al. (2017), we also used a warm-up video clip depicting a non-motion event in order to acquaint the participants with the experiment. The four settings along with the thirteen scenes used in this video set are represented below (adopted from Matsumoto et al. 2017). It should be pointed that $S$ in the following table stands for the speaker's space, which corresponds to the location of the camera from which the scene is videotaped or, in other words, where the participants are requested to imagine themselves to be. It should be also mentioned that two video-clips for each scene were made, in one of which the Figure smiled or greeted and in the other this behaviour was absent. Based on the information provided by Matsumoto et al. (2017), the smile and greeting were presented at the most natural moments of the clips as follows: (L-1, L-2, L-3, S-1, S-2, S-4, S-5: from the beginning toward the middle of motion; S-3, S-6: at the beginning of motion; C-1, C-2, C-3: at the time of entry/exit; B-1: after exit). It is worth mentioning that before starting the task, participants were requested to pay attention to some oral instructions about completing the task. The language of the instruction was IK. Accordingly, participants, sitting in front of a laptop, were requested to watch the video-clips portraying the motion events. 
They were also instructed to imagine themselves there in the scene and definitely in the speaker position (so in the location of the camera where the scene is videotaped), while assuming that the Figure is his/her friend and then tell the experimenter what they have seen. Finally, their descriptions were recorded and transcribed for further analysis.

L: Lawn (Open space)

L-1 motion toward the speaker

L-2 motion off to a side of the speaker

L-3 motion across in front of the speaker

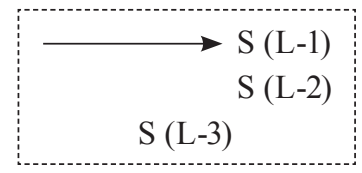

C: Classroom

C-1 motion into the classroom toward the speaker

C-2 motion into the classroom off to a side of the speaker

C-3 motion out of the classroom across in front of the speaker (who is at another door)

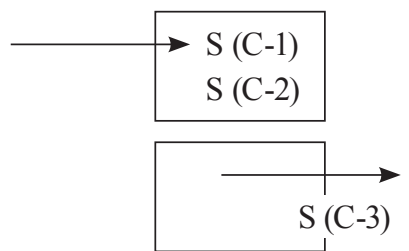

S: Staircase outside a building

S-1 motion onto the speaker's level toward the speaker

S-2 motion onto the speaker's level across in front of the speaker

S-3 motion onto the speaker's level away from the speaker

S-4 motion onto some other level toward the speaker

S-5 motion onto some other level across in front of the speaker

S-6 motion onto some other level away from the speaker
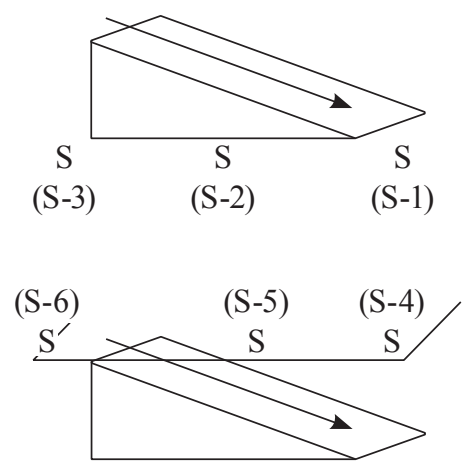

B: Building

B-1 motion out of the building across in front of the speaker (who is outside the building)

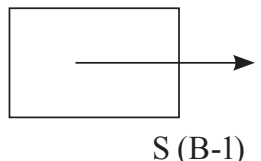

Table 1. Video stimuli used: 13 scenes (Matsumoto et al. 2017) 


\subsection{Results}

The results of the experiment are presented in the following sub-sections.

\subsubsection{Frequency of deictic verb and other PPs/ VPs in IK}

In this section, based on the descriptions of the participants, the frequency of deictic verb and other PPs/VPs used in IK will be indicated. It should be pointed that in order to show the status of IK among other languages of the same or different typological class, there will be cross-linguistic comparison with the languages studied by Matsumoto et al. (2017), namely English, Japanese and Thai.

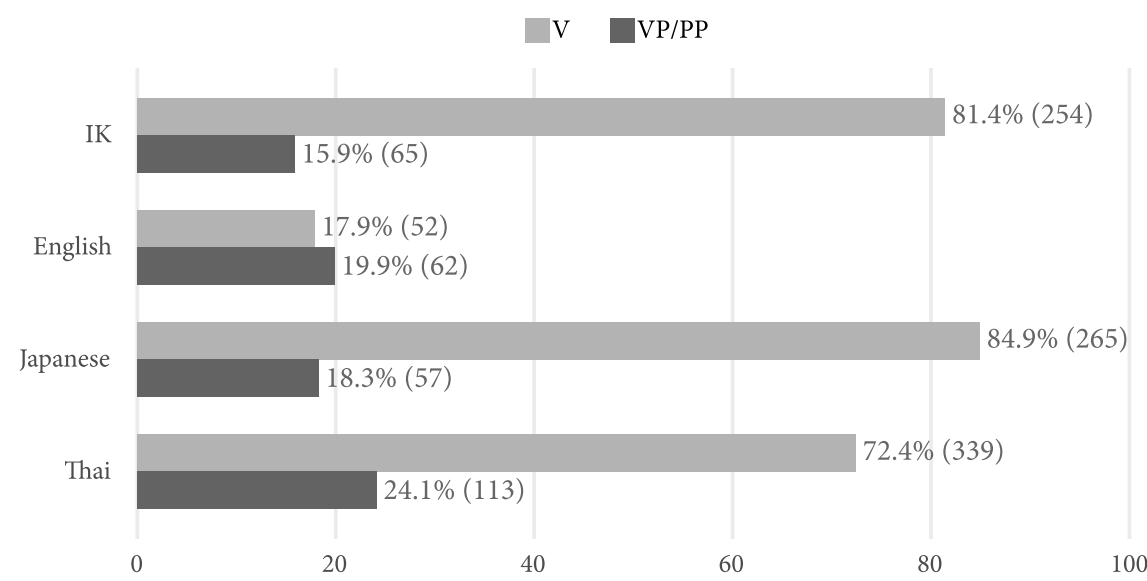

Figure 1. The V (verbal) and PP/VP indications of deixis in IK and other languages with the observed frequencies in parentheses (average rates of use per clip)

The overall frequency of the deictic verb hatan used by IK participants is $81.4 \%$, which shows that IK speakers consider this way of encoding deictic motion as the main strategy. On the contrary, as the statistics shows, using other VPs/PPs to express deictic motion is restricted in this dialect; the overall frequency of other VPs/PPs in the descriptions of the video-clips was $15.9 \%$, which is remarkably lower than that of the venitive verbs. Comparing the results of IK and other languages shown in Fig. (1), we notice that IK shows a great difference with English as far as the frequency of venitive verbs is taken into account ( $81.4 \%$ vs. $17.9 \%$, respectively). However, the frequency of the deictic verb used in IK does not show such a difference, as far as Japanese $(84.9 \%)$ and Thai $(72.4 \%)$ are concerned. On the other hand, the use of other $\mathrm{VPs} / \mathrm{PPs}$ does not show a remarkable difference across all languages. The frequency of other VPs/PPs used in IK is $15.9 \%$, which is not remarkably different compared with the frequencies reported for English (19.9\%), Japanese (18.3\%) or Thai (24.1\%). The VPs used for IK were nazik bijan 'approaching' aw re kxeftan 'start walking' and the venitive PPs observed was wera ma 'towards me', le ma 'behind me' and woera pirijam 'in my direction'. It should be also noted that in all the cases where PPs encode the deictic motion, the first person was necessarily explicated. By contrast, 
although some of the VPs explicate the first person (i.e. speaker), there were also some cases in which this component was absent. The following examples illustrate this point concerning the former:

(11) zan-ce nazik-aw bi. woman-DEF near-toward become.PST.3SG

The woman approached.

(12) zan-ce nazik-am-aw bi. woman-DEF near-me-toward become.PST.3SG The woman approached me.

As can be seen above, in example (11) no item refers to the speaker and this concept can be inferred implicitly. On the other hand, the first person pronoun am 'me' as an inflectional affix functions to explicate the goal of deictic motion, which is the speaker. It is worth mentioning that in $93 \%$ of the elicited data, the first person pronoun has been explicated and in only $7 \%$ of the cases this component was absent.

\subsubsection{The encoding of venitive verbs in IK in different controlled contexts}

After specifying the overall frequency of the use of deictic verb and other VPs/PPs in IK and the status of this dialect among other languages of the same and different typological class, now we report the results concerning the functional effects of the use of venitive verbs based on four different scenes including presence vs. absence of the speaker's space, speaker's space 1: classroom, speaker's space 2: staircase levels, and speaker's space 3: visible space (Matsumoto et al. 2017).

\subsubsection{Presence vs. absence of the speaker's space}

For the purpose of this sub-experiment, L-1 scene, portraying motion toward the speaker in an open space, C-1 scene, showing motion toward the speaker into his/ her space and S-1 scene, indicating a motion down onto the speaker's level are analyzed. The visualizations of these scenes are represented in Fig. (2). In this section, we intend to show how IK participants encode the venitive verb in these different contexts. In order to make the results of this section comparable with Matsumoto et al.'s (2017) research, we present the results of the video-clips which involve the interactional behaviour (i.e. greeting or smiling at the speaker) of the Figure.

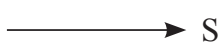

a) Open space

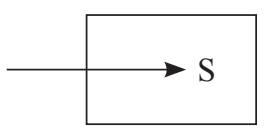

b) Classroom

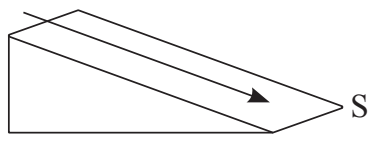

c) Staircase

Figure 2. Scenes used to test the effects of the presence/absence of the speaker's space (Matsumoto et al. 2017) 
Analyzing the IK data in this respect, we notice that in $100 \%$ of the cases IK participants have used the venitive verb haton 'coming' to encode the relevant motions. This high frequency of using the venitive verb shows that regardless of the speaker's space or direction of the motion (into vs. onto), IK speakers consider the venitive verb as the main strategy to encode such motions. The frequency of the used venitive verbs in IK and the languages studied by Matsumoto et al. (2017), which can better show the status of IK among other languages, are represented in Fig. (3).

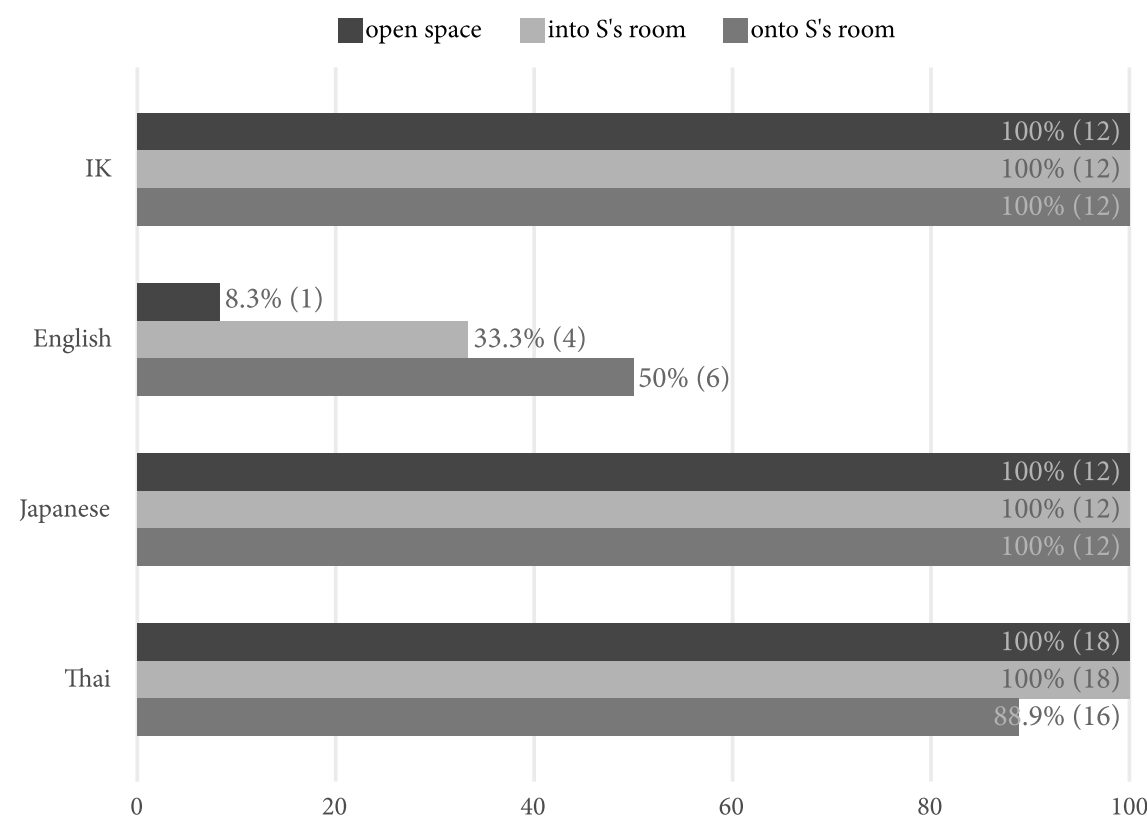

Figure 3. The use of venitive verbs for scenes with and without the speaker's space in IK and other languages with the actual frequencies in the parentheses (average rates of use per clip)

According to Fig. (3), IK, Japanese and Thai participants have similarly responded to the video-clips in terms of using venitive verbs. In other words, the speakers of these languages have frequently used their venitive verbs to depict the relevant motions. Accordingly, IK and English show differences at all three levels, i.e. motion in open space (100\% vs. $8.3 \%)$, into speaker's room (100\% vs. $33.3 \%)$ and onto speaker's level (100\% vs. 50\%). As has been pointed by Matsumoto et al. (2017), English participants do not tend to frequently use venitive verbs to describe these motions, except when the goal of motion is based in the speaker's space. The actual IK examples for three different scenes are given below.
(13) roefiq-oem
hat
woraw ma.
friend-DEF.me come.PST.3sg toward me
My friend came toward me. 

(14) reefiq-om hat-(w)xe nam-s ataq-œ.
friend-DEF.me come.PST.3SG-to into room
My friend came into the room.
(15) roefiq-om hat-aw xwar. friend-DEF come.PST.3sG down
My friend came down.

As can be seen in example (13), which has been used to describe L1 scene, the venitive verb with the adpositional phrase woraw ma 'towards me' has been used. Similarly, in examples (14) and (15), which respectively portray motion toward the speaker into his/her space and down onto the speaker's level (i.e. the C1 and S-1 scenes), the venitive verb has been used. By analyzing the examples mentioned above, we figure out that venitive adpositions are more frequently used to describe motion in an open space such as L1. Having said that, the manipulation of the directional factors, as is the case in $\mathrm{C}_{1}$ and S-1 scenes, can enhance the use of directional or path coding adpositions and restrict the use of deictic adpositions. For this reason, example (13) occurring in an open space includes the deictic expression woraw ma 'towards me', but focusing on the direction of motion, the last two examples express the direction of motion, i.e. nama ataqee 'to inside the room' and - aw xwar 'towards down'. Naturally, in these examples the deictic concept conflated with the verb can let the language users notice the moving is directed towards the speaker.

\subsubsection{Speaker's space 1: Classroom}

In this section, the descriptions of the L-2 and C-2 clips are evaluated to see how frequent IK participants encode the venitive verb, when the Figure moves slightly off the direction of the speaker into or onto his/her space. The visualizations of the relevant clips are given below.

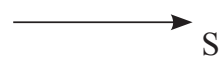

a) Motion slightly off the speaker's direction in an open space

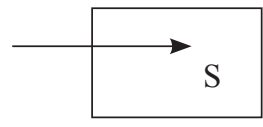

b) Motion slightly off the speaker's direction into his/her space (room)

Figure 4. Scenes used to test the effects of the speaker's space 1: Room (Matsumoto et al. 2017)

As can be observed in Fig. (4), L-2 and C-2 clips are different, since the motion in L-2 takes place in an open space, while the latter shows a motion taking place in a closed space. In particular, we intend to test whether IK participants consider this difference in their descriptions or not. Similar to the previous sub-experiments, we compare the results of IK with the languages studied by Matsumoto et al. (2017), which helps us to specify the status of IK from a typological perspective.

The results concerning IK and other languages are shown in Fig. (5). 


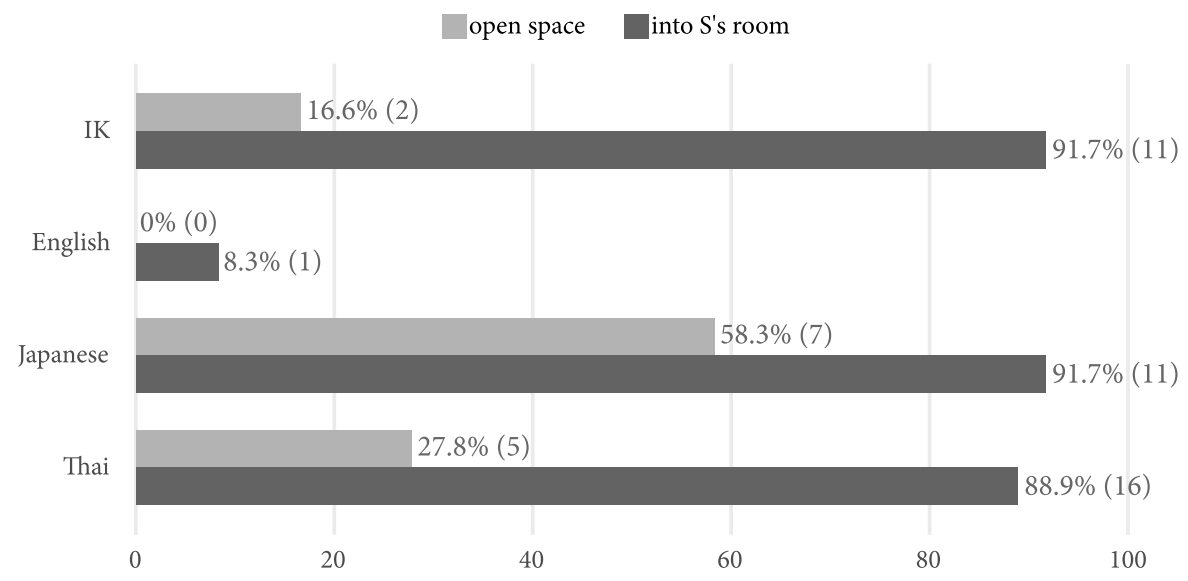

Figure 5. The use of venitive verbs for motion off S's direction into / not into S's room in IK and other languages with the actual frequencies in the parentheses (average rates of use per clip)

According to the results, IK participants are sensitive in using the venitive verb hatan 'coming' based on the presence or absence of the speaker's space. Examining the IK data, we notice that when the Figure moves off the direction of the speaker in an open space, participants do not tend to describe the motion using the venitive verb. In some cases, they use other verbs such as roed bijan 'passing by' and even andative verb tfagan 'going' to describe the motion event, which can be seen in the actual examples (16) and (17) given below. In contrast with the descriptions of the L-2 scene, IK participants use the venitive verb haton 'coming' to describe the motion which takes place into the speaker's space as in example (18). Comparatively, IK participants have used the venitive verb more often than English participants for both open and closed spaces (16.6\% vs. 0\%; $91.7 \%$ vs. $8.3 \%$, respectively). However, IK participants have used the venitive verb less frequently than both Japanese and Thai participants in their descriptions of the motion in the open space ( $16.6 \%$ vs. $58.3 \%$ vs. $27.8 \%$, respectively); the statistics obtained for the descriptions of motion into speaker's room (i.e. closed space) shows that IK speakers and Japanese participants have equally (both 91.7\%) used the venitive verb, while Thai statistics indicate a bit less percentage of usage (88.9\%).

(16) reefiq-œem doe la-m reed-aw bi.

Friend-DEF.me from side-me pass become.PST.3sG

My friend passed by me.

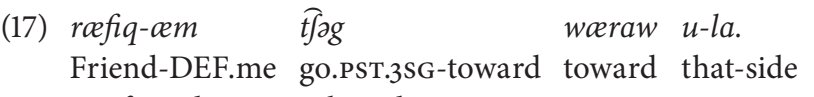

My friend went to the side. 
(18) roefiq-cem wej-law hat.

Friend-DE.me this-side come.PST.3SG

My friend came from this side.

In example (16), the direction of the motion and the speaker doe lam 'beside me' are encoded along with the verb rodaw bijon 'passing by'. Accordingly, in this example the VIA path of motion has been described. In example (17), the motion is not considered a deictic motion at all, since an andative verb has been used to describe the motion and the goal of motion is somewhere other than the speaker's location (i.e. woraw ula 'toward the side'). As results show, these items are more frequently used, when motions take place in an open space. However, in example (18), since the space is closed and the goal of motion is within the speaker's space, the venitive verb hatan has been used along with the direction of the motion (wejlaw 'on this side'), which implies that the motion takes place slightly off the direction of the speaker.

\subsubsection{Speaker's space 2: staircase levels}

In this section, we examine how frequently IK participants use venitive verbs for S-1 through S-6 scenes. As can be observed, in Fig. (6a) the goal of motion is in the speaker's space, but in Fig. (6b), the goal of motion is a level other than the speaker's space. As clarified by Matsumoto et al. (2017), motions onto the speaker's level and some other level consist of three different directions including 'Toward S', 'Neutral', and 'Away from S'. It is worth mentioning that 'Toward the speaker onto some other level' is not the same as in 'onto the speaker's level', simply because in the latter the level of the Figure and the speaker is the same.

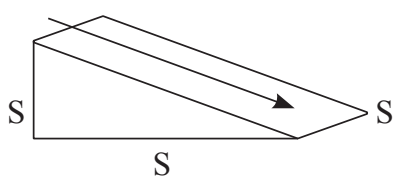

a) Motion onto the speaker's level

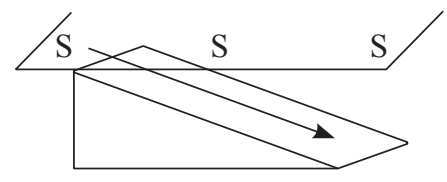

b) Motion onto some other level

Figure 6. Scenes used to test the effects of the speaker's space 2: Staircase levels (Matsumoto et al. 2017)

Evaluation of the IK data indicates that IK participants tend to use venitive verbs more frequently, when the motion takes place onto the speaker's level. This pattern of use is seen in English, Japanese and Thai as reported by Matsumoto et al. (2017), too. The percentage of the use of venitive verbs in different languages including IK is presented in Fig. (7).

Based on the analysis of the IK data, it can be said that the speaker's space plays an important role in the enhancement of venitive verb usage in this dialect. Concerning motion onto levels other than the speaker's, it is shown that IK participants have used venitive verbs less frequently for all the three directions: Toward S (25\%), Neutral (8.3\%) and Away from S (8.3\%). In contrast, when the motion is onto the 


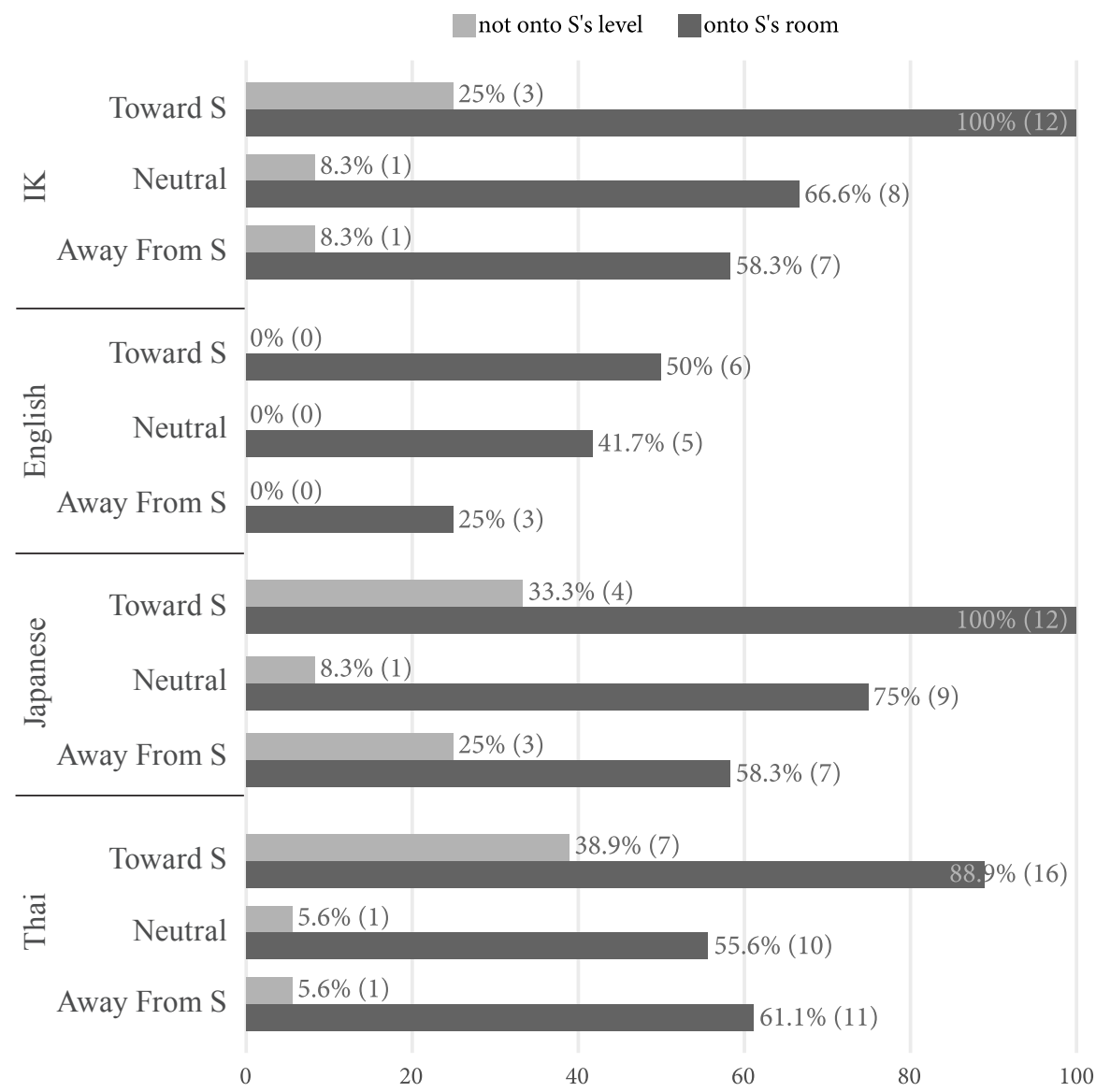

Figure 7. The use of venitive verbs for different directions of motion onto/not onto S's level in IK and other languages with the actual frequencies in the parentheses (average rates of use per clip)

speaker's space, the percentages of the use of the venitive verbs remarkably increase. The percentage of the venitive verb used for the three directions onto the speaker's space including Toward S, Neutral, and Away from S is $100 \%, 66.6 \%$ and $58.3 \%$, respectively. This statistics highlights the importance of the speaker's space in the encoding of venitive verb by IK participants, in comparison with the direction of motion which seems to be less decisive vis-à-vis the frequency of venitive verbs. This point is illustrated by the following examples which are the descriptions of S-1 (motion onto the speaker's level toward the speaker) and S-4 (motion onto some other level toward the speaker) scenes.

(19) reefiq-om doe pal-ae hat-aw xwar. Friend-DEF.me from stair-DEF come.PST.3sg down My friend came down the stairs. 
(20) roefiq-cem doe pal-œe ţag-aw xwar.

Friend-DEF.me from stair-DEF go.PST.3SG down

My friend went down the stairs.

In the visualizations of these scenes, it can be seen that both motions are toward the speaker. In spite of this similarity, the S-1 scene takes place onto the speaker's level, which has been encoded by the venitive verb hatan 'coming' in example (19). In example (20), which is used to describe the S-4 scene, on the other hand, the participant has avoided the use of the venitive verb, since the motion takes place onto some other level. In this example, by contrast, the andative verb ţagan 'going' has been used.

\subsubsection{Speaker's space 3: Visible space}

This section deals with the (in)visibility of the Figure in the video-clips to see the way this affects the frequency of use of venitive verbs in IK. The scenes which are evaluated in this respect are L-3, B-3, and C-1, which are visualized in Fig. (8).

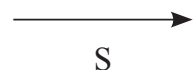
a) Motion in an open space
b) Visible-to-visible exiting

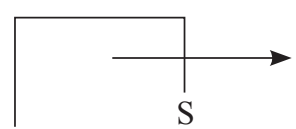

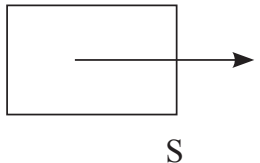

c) Invisible-to-visible exiting

Figure 8. Scenes used to test the effects of visibility (Matsumoto et al. 2017)

The L-3 scene shows a motion taking place across the open space in front of the speaker. The B-3 and C-1 scenes, on the other hand, indicate that the starting point of the motion is inside a closed space (i.e. a building), but the goal of motion is based outside the building. It should be pointed out that in the B-3 scene, the speaker, located at another door of the building can see the Figure both inside and outside the building. In contrast, in the $\mathrm{C}-1$ scene, the Figure is only visible to the speaker when he/she exits the building, since the speaker (or in fact the camera) is located outside the building. The percentages of the use of venitive verbs in IK are given in Fig. (9). As previously stated, in order to specify the status of IK among other languages, the results concerning English, Japanese and Thai (Matsumoto et al. 2017) are also included in the Figure.

According to Fig. (9), IK participants do not tend to use venitive verbs to describe the motion taking place across the open space in front of the speaker at all, so that the percentage of the use of the venitive verb for L-3 is o\%. This low frequency is also the case in other languages; the percentage of the use of venitive verbs in English, Japanese and Thai is $0 \%, 0 \%$ and $5.6 \%$, respectively. On the contrary, IK participants have used the venitive verb more often (25\%) as far as the B-3 scene is considered. However, this is comparatively less than the percentage gained for the C-1 scene which is equal to $100 \%$. This shows that the process in which the Figure changes from 


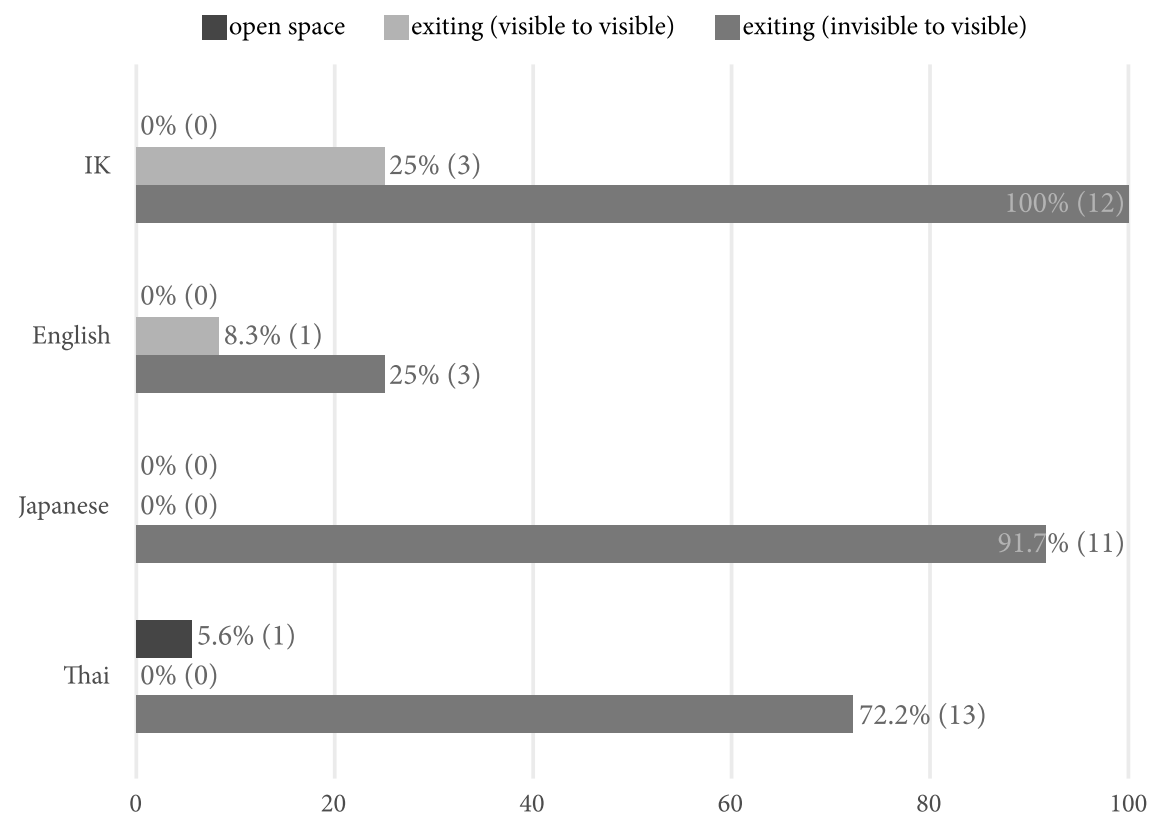

Figure 9. The use of venitive verbs for the scenes testing visibility contrast in IK and other languages with the actual frequencies in the parentheses (average rates of use per clip)

invisible to visible can be a determining factor by which the percentage of the use of the venitive verb can be enhanced. This pattern seems to be cross-linguistically widespread, as is relatively attested in Japanese, Thai and also English.

As it was mentioned, in $25 \%$ of the IK descriptions concerning the B- 3 scene, the venitive verb has been used. Note that in the remaining $75 \%$ of the descriptions, the motion is conceptualized as a 'going' event, so that in all these descriptions the andative verb tfogan 'going' has been used. This contrast is illustrated in the following examples.

(21) reefiq-om doe mal-ce hat-aw doer. friend-DEF.me from house-DEF come.PST.3SG-towards out My friend came out of the house.

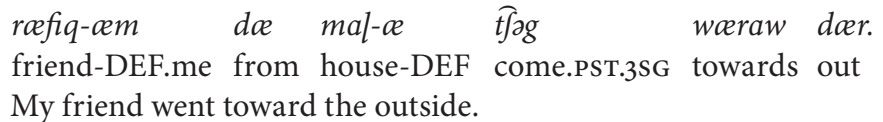

The actual instances given above have been used to describe the B-3 scene from different perspectives. According to example (21) which includes a venitive verb, the motion is described so that the moving person is approaching the speaker. On the contrary, in example (22) which includes an andative verb, the event is conceptualized in such a way that it is oriented away from the deictic centre. 
One other thing worth mentioning concerns the morphological constructions of the venitive verbs used for B-3 and C-1. It appears that the (in)visibility of the Figure is linguistically encoded in the descriptions of the respective scenes. The following examples are illustrative.

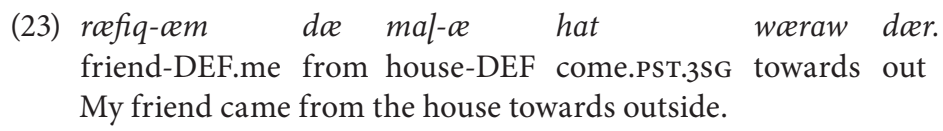

(24) roefiq-om doe mal-ce dor-(h)at.

friend-DEF.me from house-DEF out-come.PST.3SG

My friend came out of the house.

In example (23), which describes the B-3 scene, hatan 'coming' as the venitive verb is encoded along with woraw doer 'towards outside', which shows the direction of the Figure visible to the speaker both inside and outside the building. However, in example (24) portraying the C-1 scene, the venitive verb is encoded along with a directional morpheme (dar 'out'), which implies that the Figure abruptly becomes visible to the speaker. Accordingly, it seems safe to claim that the directional items add some kind of information to the venitive verb based on the visibility or invisibility of the Figure.

\subsubsection{The effect of interactional behaviour on the encoding of the venitive verb in IK}

As stated previously, following Matsumoto et al. (2017), each of the scenes used in this experiment was made twice, so that one video-clip for each scene portrayed the person in motion smiling at or greeting the speaker. This enabled us to measure the effect of interactional behaviour on the encoding of venitive verbs in IK. The results of this sub-experiment along with the results reported for English, Japanese and Thai (Matsumoto et al. 2017) are presented in Fig. (10).

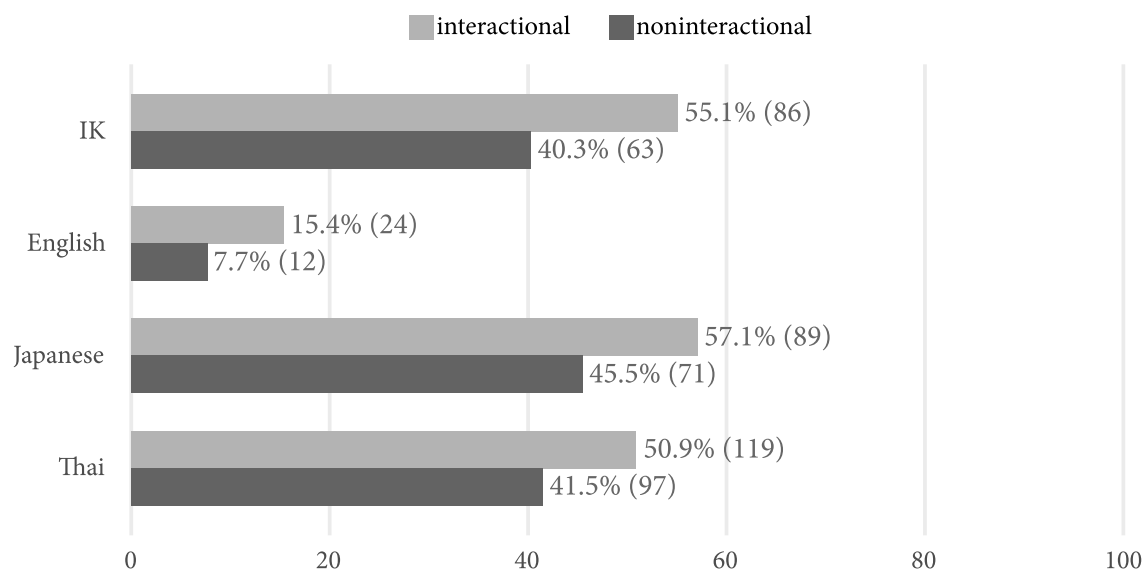

Figure 10. The use of venitive verbs for all the scenes with and without interactional behaviour in IK and other languages with the actual frequencies in the parentheses (average rates of use per clip) 
Based on the results presented above, it can be said that the overall percentage of the use of venitive verbs is enhanced, when the scene is accompanied by the interactional behaviour of the moving person. Fig. (10) indicates that in $55.1 \%$ of the scenes, in which the person smiles at or greets the speaker, venitive verbs have been used by IK participants to describe the motions. This is slightly less than Japanese (57.1\%) and more than Thai (50.9\%), but shows a greater difference in comparison with English (15.4\%). The absence of the interactional behaviour seems to affect the encoding of the venitive verb in IK. It appears that in the absence of greeting or smiling at the speaker, there is a decrease in the use of venitive verbs. In $40.3 \%$ of the descriptions without the mentioned interactional behaviour, the venitive verb has been used by the IK participants, which shows a similar pattern to the one observed in Japanese (45.5\%). The proportions of verbs which fit this pattern were $7.7 \%$ and $41.5 \%$ in English and Thai, respectively.

In order to highlight the effect of the interactional behaviour of the Figure in IK, we present the results concerning the staircase scenes with and without the interactional behaviour in Fig. (11). The results of English, Japanese and Thai (Matsumoto et al. 2017) are also provided for comparison.

As shown, IK participants have explicated the venitive verb in $100 \%, 66.6 \%$ and $58.3 \%$ of the descriptions for the S-1, S-2 and S-3 scenes, respectively, when the scenes are accompanied with the greet or smile of the Figure. The percentages are all lower in the corresponding scenes, when the interactional behaviour is absent, so that in $91.7 \%, 41.7 \%$ and $16.6 \%$ of the corresponding scenes without the interactional behaviour, the venitive verb has been explicated. Accordingly, the lowest percentage is related to the scene in which the Figure moves away from the deictic centre without any interactional behaviour, confirming that the interactional behaviour of the Figure can motivate the participants to use the venitive verb in their productions. Comparing IK, English, Japanese and Thai, we notice that the presence of the interactional behaviour is cross-linguistically attested in all the languages listed above, however the degree of this effect varies across languages depending on their intra-language features. The following examples illustrate the use of the venitive verb for the S-3 scenes with interactional behaviour and non-use of the venitive verb for the same scenes without the interactional behaviour of the Figure.

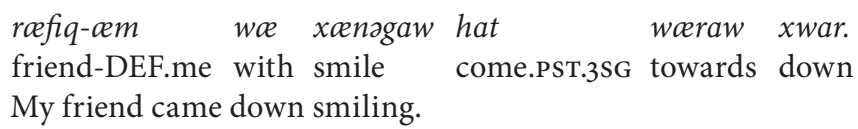

(26)

$\begin{array}{llll}\text { ræefiq-am } & \text { mel-a } & \text { xwar } & \widehat{t} f \partial g . \\ \text { friend-DEF.me toward-EZ } & \text { down } & \text { go.PST.3sG } \\ \text { My friend went down. } & \end{array}$

Clearly, the presence of the interactional behaviour (i.e. smiling) has motivated the participant to describe the motion through the venitive verb in example (25). The absence of this behaviour shows that participants may conceptualize the event outside the speaker's space, so that the scene has been described using the andative verb ţagan 'going' in example (26). 


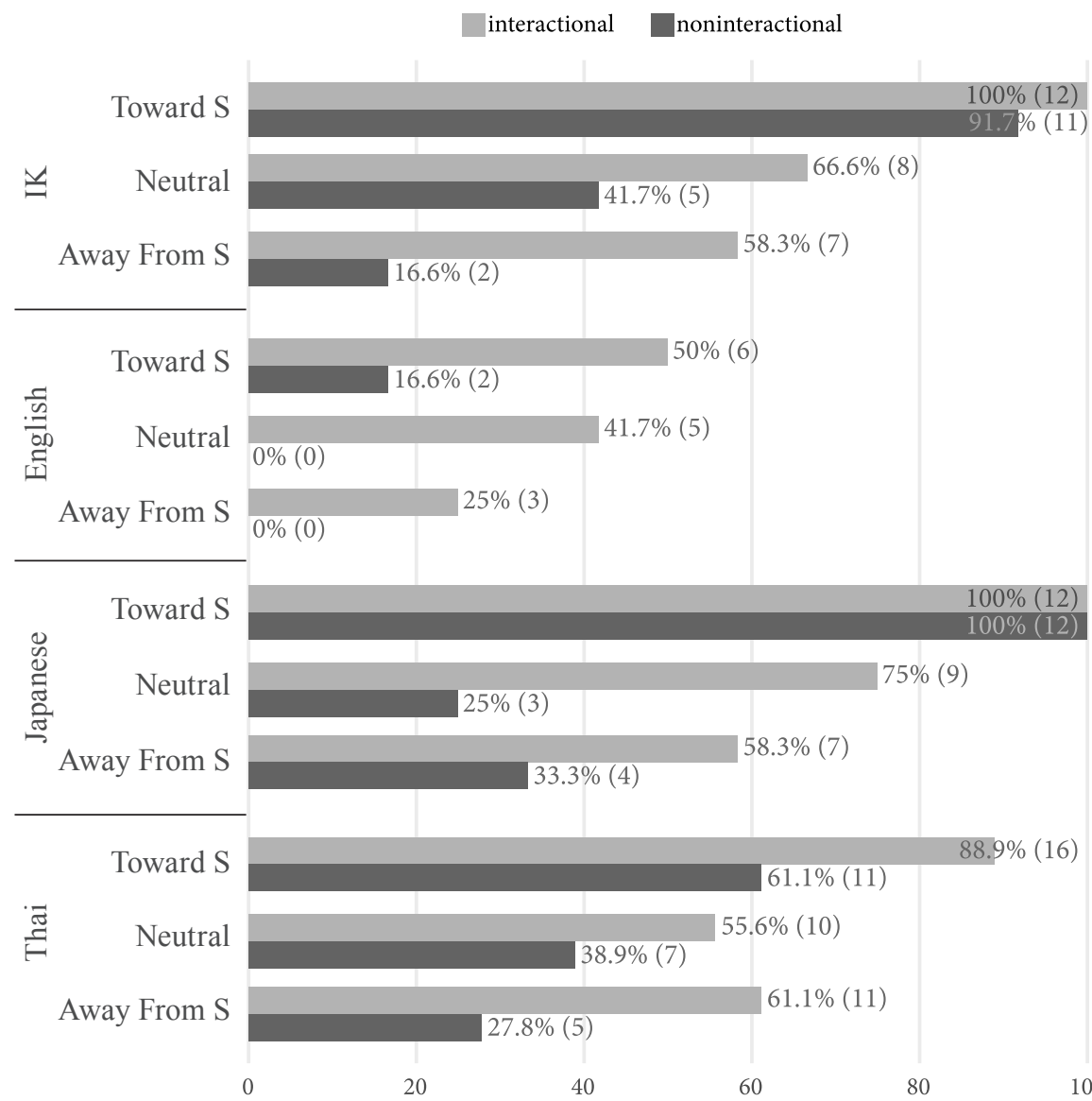

Figure 11. The use of venitive verbs for staircase scenes with and without interactional behaviour with the actual frequencies in the parentheses (average rates of use per clip)

\subsubsection{The encoding of venitive PPs/VPs in IK}

So far, the frequency of use of venitive verbs in the descriptions of IK participants has been shown. It was statistically discussed that IK participants more often explicate the venitive verbs in their descriptions and the frequency of the encoding of venitive verbs is affected by factors such as the interactional behaviour and (in) visibility of the Figure. In this section, the frequency of other venitive PPs/VPs in the descriptions of the IK participants is discussed. For the purpose of this discussion, L-1, C-1 and S-1 scenes, as visualized in Fig. (2), and S-1 through S-6 scenes, as visualized in Fig. (6), will be evaluated. In addition to IK, the results concerning English, Japanese and Thai (Matsumoto et al. 2017) are also provided, which can facilitate the specification of the status of IK from a cross-linguistic point of view. 


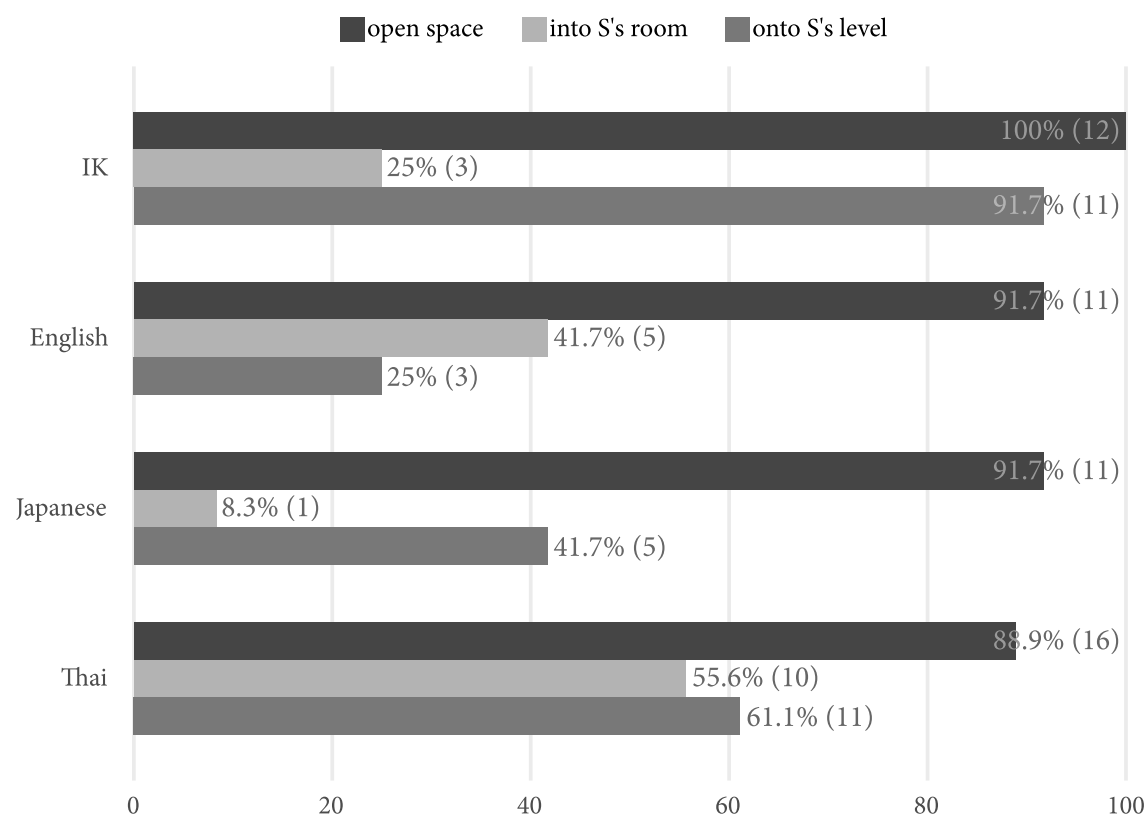

Figure 12. The use of venitive PPs/VPs for three scenes with and without the speaker's space in IK and other languages with the actual frequencies in the parentheses (average rates of use per clip)

Results reveal that IK participants tend to include a venitive PP/VP in their descriptions all the time as far as L-1 is considered. According to Fig. (12), in 100\% of the cases, IK speakers have used a venitive PP/VP to describe the deictic motion in an open space. IK shows a slight difference in comparison with English (91.7\%), Japanese (91.7\%) and Thai (88.9\%). The percent of the use of venitive PPs/VPs is frequent in the descriptions of the S-1 scene, as well. Statistically, in $91.7 \%$ of the IK descriptions in this respect a venitive PP/VP has been used, which shows a higher tendency in comparison with the other languages (English: 25\%; Japanese: 41.7\%; and Thai: 61.1\%). In contrast, the use of venitive PPs/VPs for the C-1 scene is limited compared to L-1 and S-1 scenes; venitive PP/VPs has been used in only $25 \%$ of the relevant descriptions, which is low in comparison with the other scenes evaluated. The percentage of the use of venitive PPs/VPs for the C-1 scene in other languages are as follows: English (41.7\%); Japanese (8.3\%); and Thai (55.6\%). Based on these findings, it seems safe to conclude that in the deictic motion of the Figure in an open space as in the L-1 scene and also onto the speakers level as in the S-1 scene, the spatial direction of the motion is secondary or less important, which means that speakers tend to imply this information in favour of venitive PP/VPs. However, the IK participants more often encode the spatial direction of the motion, when it takes place in the speaker's room as shown in the C-1. This sets an upper limit on the use of venitive PPs/VPs, when the $\mathrm{C}-1$ scene is described in IK. The following examples are illustrative for the L-1, C-1 and S-1 scenes, respectively. 
(27) roefiq-om we xoeng woraw ma hat.

friend-DEF.me with smile toward me come.PST.3sG

My friend came toward me smiling.

(28) reefiq-am hat-aw nam-a staq-œ.

friend-DEF.me come.PST.3SG- toward into-EZ room-DEF

My friend came into the room.

(29) roefiq-oem woraw ma hat.

friend-DEF.me toward me come.PST.3SG

My friend came toward me.

In example (27), which is the description of the L-1 scene, the venitive verb haton 'coming' is used along with woeraw ma 'toward me', which is a venitive PP. In example (28), which portrays the $\mathrm{C}-1$ scene, no specific venitive $\mathrm{PP} / \mathrm{VP}$ has been used along with the main venitive verb, and the path of motion (aw nama ataqoe 'toward into the room') has been explicated instead. Although the direction of motion is manipulated in the S-1 scene, example (29) does not encode any spatial component, since the participant has preferred to highlight the deictic motion through using the venitive PP, woraw ma 'toward me', instead of describing the spatial direction of the motion. The S-1 through S-6 scenes can also show how frequently IK speakers explicate PPs/VPs in their descriptions. The frequency of the use of venitive PPs/VPs in IK is provided below, with the frequency of other languages studied by Matsumoto et al. (2017).

Depending on whether the motion takes place onto the speaker's level or in other levels, IK participants decide to use venitive PPs/VPs or otherwise. The percentage of the use of venitive PPs/VPs in IK for the motion not onto the speaker's level is as follows: Toward S: 16.6\%; Neutral: O\% and Away from S: O\%. This statistics shows that IK participants infrequently use venitive PPs/VPs to describe motions towards the deictic centre onto other levels and do not tend to explicate a venitive PP/VP for Neutral and Away from S motions at all. When the motion takes place towards the speaker onto his/her level, venitive PPs/VPs have been used in $83.4 \%$ of the descriptions, which is remarkably high. This is $8.3 \%$ and o\% as far as 'Neutral' and 'Away from S' motions are concerned. The frequency of the use of venitive PPs/VPs in other languages can be observed above. Analyzing the IK data, we can notice that when participants conceptualize the goal to be very close to the speaker at the end of motion, they are more likely to use PPs in their descriptions to emphasize this proximity between the Figure and the speaker. This has enhanced the use of venitive PPs in 'Toward S' motions onto the speaker's level. Moreover, the nature of the motions and according higher priority to spatial direction in other motions can account for why the use of venitive PPs/VPs is infrequent in those cases. First, based on the statistics presented in Fig. (13), IK speakers too infrequently had used the venitive verbs to describe motions such as Neutral and Away from $S$ onto S's level (8.3\% and 6.3\%, respectively), because they sometimes conceptualize such motions as andative rather than venitive movements. Accordingly, we can no longer expect 


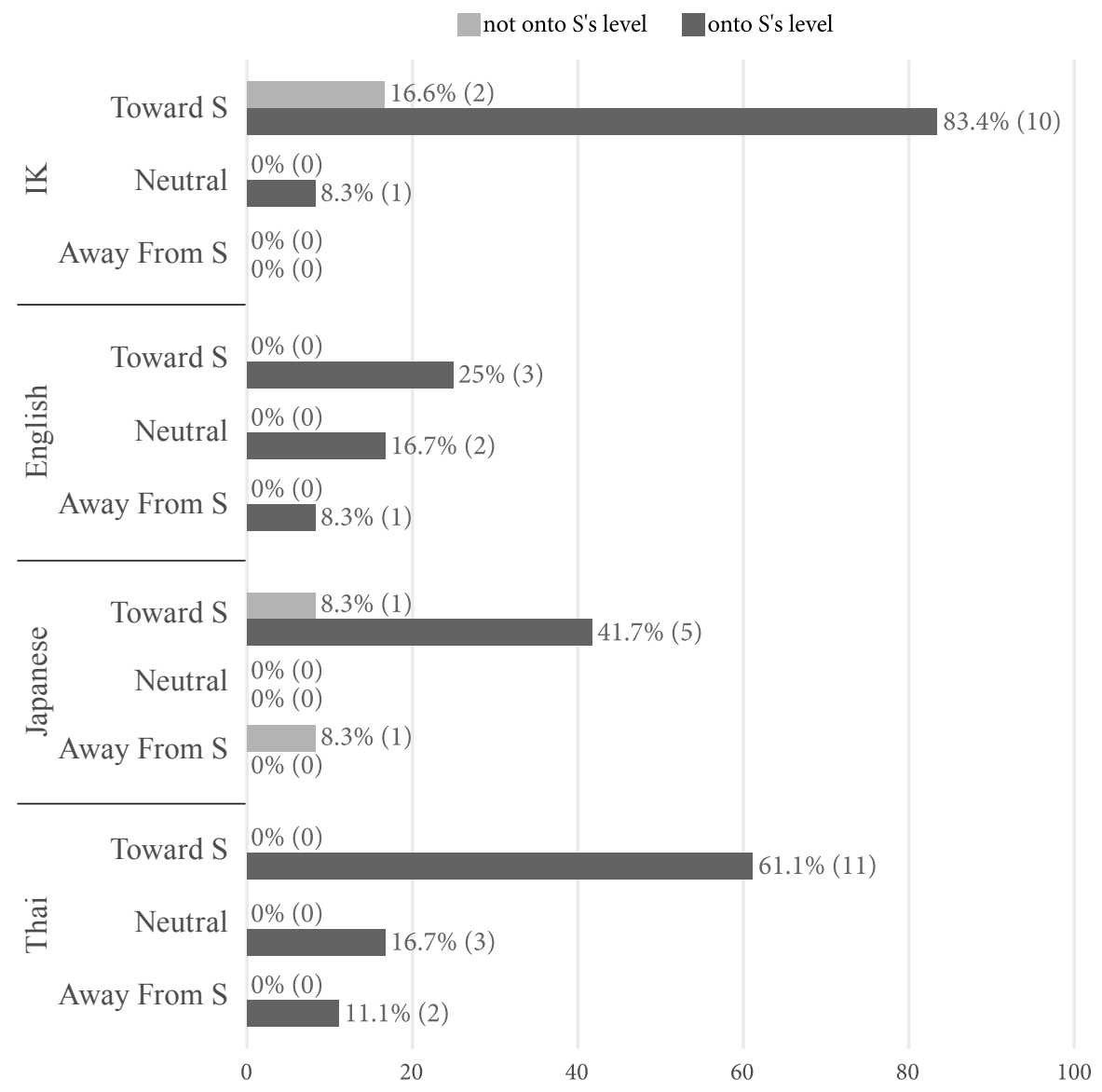

Figure 13. The use of venitive PPs/VPs for different directions of motion onto/not onto S's level in IK and other languages with the actual frequencies in the parentheses (average rates of use per clip)

the IK participants to use venitive PPs/VPs for the description of andative motions. Second, the participants, who conceptualize the motions as venitive movements, may accord higher priority to the spatial direction of the motion, so that they prefer to encode the spatial goal of motion rather than the venitive adposition along with the main verb.

Since the examination of IK data shows that none of the participants has used venitive PPs/VPs to describe the motions including the (in)visibility of the Figure, further evaluation of these scenes is pointless for the purpose of this discussion. Then, we intend to show how frequently IK speakers use venitive PPs/VPs in all the 26 scenes with and without the interactional behaviour of the Figure. The results of this evaluation are provided in Fig. (14). 


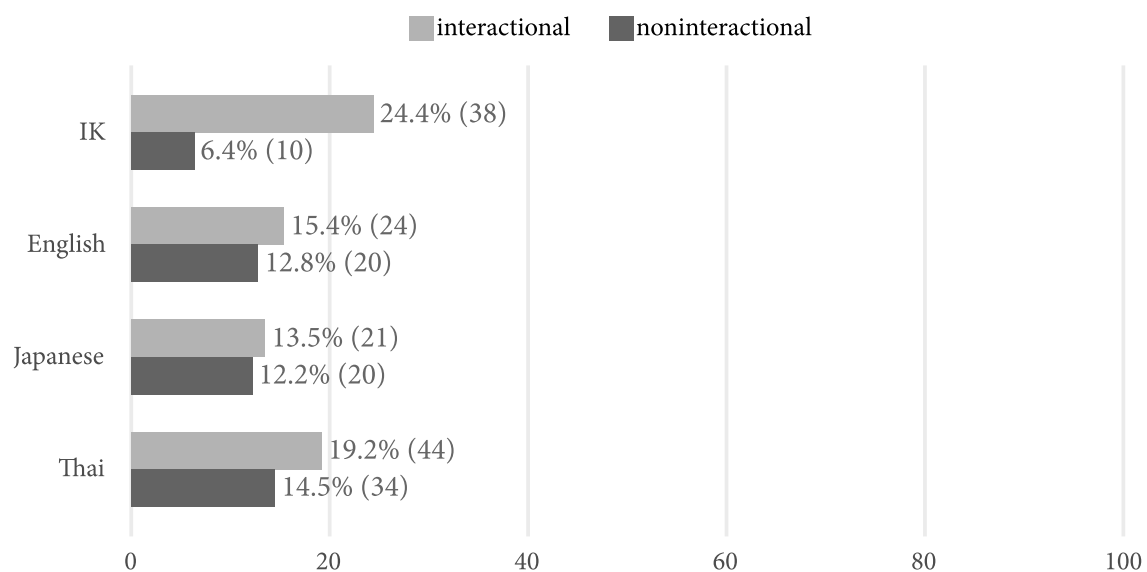

Figure 14. The use of venitive PPs/VPs for all the scenes with and without interactional behaviour in IK and other languages with the actual frequencies in the parentheses (average rates of use per clip)

Evidently, the presence of interactional behaviour can also remarkably enhance the encoding of venitive PPs along with the verb in IK. In $24.3 \%$ of the scenes with interactional behaviour of the Figure, venitive PPs/VPs have been used, while the mentioned venitive phrases have been used in $6.4 \%$ of the descriptions concerning the scenes without the interactional behaviour. This again is attributed the conceptualization of the motions by participants; when they believe that the goal of motion is very close to or overlaps with the speaker, it is more probable that they use a venitive $\mathrm{PP}$ in their descriptions. The statistics gained for other languages by Matsumoto et al. (2017) shows that the frequency on the use of venitive PPs/VPs is slightly higher, when the motion is accompanied by the interactional behaviour of the Figure.

\section{Discussion}

IK speakers use the venitive verb haton 'coming' as the basic way of describing deictic motions toward the speaker. Based on the video-based experiment, it was shown that the percent of the use of venitive verbs is enhanced in the presence of functional factors, such as interaction and visibility of the Figure, as well as interactional behaviour of the Figure, such as smiling at the speaker. This pattern has been attested in other languages including English, Japanese and Thai as reported by Matsumoto et al (2017). They believe that according to their findings, one can claim that deictic expressions and venitive verbs in particular are not only spatial but also functional in nature. However, as they claim, English as a satellite-framed language, which mainly encodes path outside the verb root through adpositions and conflates the manner component with the main verb, shows relatively less tendency to encode the venitive verb come, as the slot also competes for encoding manner of 
motion. As shown in this paper, IK participants exhibit relatively high tendency to encode the venitive verb in their descriptions of the relevant scenes.

Analyzing the IK data, we can notice that along with the venitive verb haton 'coming', some other elements can be expressed, too. For the purpose of this discussion, the encoding of venitive PPs and other path-coding components are important. As pointed previously, IK allows the encoding of goal of motion through a separate adposition along with the venitive verb. It would seem that how the functional factors such as interaction and also interactional behaviour of the Figure are perceived by the participants can be determining in the use of venitive PPs. Accordingly, when participants realize that the goal of motion is very close to or overlaps with the speaker at the end of motion (as triggered by functional factors and the interactional behaviour of the Figure), it is very probable that they encode venitive adpositions along with the venitive verbs. The absence of these venitive PPs along with the venitive verb can be inferred so that the motion may be directed toward the speaker in a way, but it probably does not lead to that close proximity at the end of motion. On the contrary to the previous proposal (Matsumoto et al. 2017), which states that directional PPs such as toward me are not clearly functional, IK data shows that at least in this dialect, venitive PPs can contribute the venitive motions to be perceived with different levels of proximity.

\section{Conclusion}

This study was designed to examine venitive motion events in IK from a comparative perspective. In so doing, it was first discussed in what ways these events are encoded in IK. Subsequently, following Matsumoto et al. (2017), we conducted a video-based production experiment with the participation of twelve indigenous speakers of IK thereby figuring out how frequently these speakers explicate venitive verbs and other PPs/VPs in their oral descriptions in comparison with the speakers of English, Japanese and Thai (Matsumoto et al. 2017). Results of the present study revealed that IK speakers frequently encode the venitive verb haton 'coming' in their descriptions of different deictic motions. It was noticed that the frequency of the use of venitive verbs in IK can be enhanced by the interaction and visibility, on the one hand, and the interactional behaviour of the Figure, on the other hand, which was also an attested pattern observed by Matsumoto et al. (2017) in other languages. That being said, venitive PPs in IK also can be functionally used, in the sense that they co-occur with the venitive verbs, when the Figure is very close to the speaker (i.e. the Goal-Ground) at the end of motion; this is not in accordance with the proposal (Matsumoto et al. 2017) that venitive PPs are purely spatial in nature.

\section{References}

Asatrian G. 2009. Prolegomena to the study of the Kurds. - Iran and the Caucasus 13:1-58. Bynon Th. 1979. The ergative construction in Kurdish. - Bulletin of the School of Oriental and African Studies 42.2: 211-224. 
Colasacco A.M. 2019. A cognitive approach to teaching deictic motion verbs to German and Italian students of Spanish. - International Review of Applied Linguistics in Language Teaching 97.1: 71-95.

Fillmore Ch.J. 1997. Lectures on deixis. Stanford: CSLI Publications. [An earlier version published in 1975 as: Santa Cruz lectures on deixis, 1971. Bloomington: Indiana University Linguistics Club].

Gunter M. 2004. Historical dictionary of the Kurds. Maryland: Scarecrow Press.

Hampe B. 2000. Facing up to the meaning of 'face up to'. - Foolen A., van der Leek F. (eds.). Constructions in cognitive linguistics. Amsterdam: John Benjamins: 81-101.

Karimipour A., Rezai V. 2016. Typological analysis of Ilami Kurdish verbs of motion. With focus on the concept of path. - STUF - Language Typology and Universals 69.3: 411-435.

Karimipour A., Rezai V. 2019. On placement and removal events in Ilami Kurdish: A cognitive-typological approach. - Onomázein 45: 126-151.

Lindner S.J. 1983. A lexico-semantic analysis of verb-particle constructions with UP and OUT. [Series A, No 101]. Trier: L.A.U.T.

Matsumoto Y. 1996. Complex predicates in Japanese: A syntactic and semantic study of the notion 'word'. Stanford (CA): CSLI Publications \& Tokyo: Kurosio Publishers.

Matsumoto Y. 2017. Eigo ni okeru idoo-zisyoo-hyoogen no taipu to keiro-hyoogen. - Matsumoto Y. (ed.). Idoo-hyoogen no ruikeiron. Tokyo: Kurosio Publishers.

Matsumoto Y., Akita K., Takahashi K. 2017. The functional nature of deictic verbs and the coding patterns of Deixis: An experimental study in English, Japanese and Thai. Ibarretxe-Antuñano I. (ed.). Motion and space across languages. Theory and applications. Amsterdam: John Benjamins: 95-122.

Morishita Y. 2011. Doosi-renzoku-koobun ni kansuru koobun-bunpoo-teki-koosatu. - Proceedings of the annual meeting of the Japanese Cognitive Linguistics Association 11: 395-405.

Nakazawa T. 2006. Motion event and deictic motion verbs as path-conflating verbs. - Müller S. (ed.). Proceedings of the 13th International Conference on Head-Driven Phrase Structure Grammar. Varna, Stanford: CSLI Publications: 284-304.

Nakazawa T. 2009. A typology of the path of deictic motion verbs as path-conflating verbs: The entailment of arrival and the deictic center. - Poznań Studies in Contemporary Linguistics 45.3: 385-403.

Oranskij I. 1979. Iranskie yazyki v istorčeskom osveščenii. Moskva: Nauka.

Oshima D.Y. 2006a. Perspectives in reported discourse. Stanford: Stanford University. [PhD diss.].

Oshima D.Y. 2006b. GO and COME revisited: What serves as a reference point? - Annual Meeting of the Berkeley Linguistics Society 32.1: 287-298.

Takahashi K. 2009a. Thai motion event expressions: A literature review. - Minegishi M., Thepkanjana K., Aroonmanakun W., Endo M. (eds.). Proceedings of the ChulalongkornJapan linguistics symposium. [Global COE Program: Corpus-based Linguistics and Language Education]. Tokyo: Tokyo University of Foreign Studies: 29-43.

Takahashi K. 2009b. Arrival expressions in Thai. - Journal of the Southeast Asian Linguistics Society 2: 175-193.

Takahashi K. 2017. Tai-go no idoo-hyoogen. - Matsumoto Y. (ed.). Idoo-hyoogen no ruikeiron. Tokyo: Kurosio Publishers.

Talmy L. 1975. Semantics and syntax of motion. - Kimball J.P. (ed.). Syntax and semantics 4. New York: Academic Press: 181-238.

Talmy L. 1985. Lexicalization patterns: Semantic structure in lexical forms. - Shopen T. (ed.). Language typology and syntactic description. [vol. 3]. Cambridge: Cambridge University Press: 57-149. 
Talmy L. 1991. Path to realization: A typology of event conflation. - Proceedings of the Seventeenth Annual Meeting of Berkeley Linguistics Society 17: 480-519. [https://journals. linguisticsociety.org/proceedings/index.php/BLS/article/view/1620/0].

Talmy L. 2000. Toward a cognitive semantics. [vol. 2: Typology and process in concept structuring]. Cambridge, London: MIT Press.

Thepkanjana K. 1986. Serial verb construction in Thai. [PhD dissertation, University of Michigan].

Zlatev J., Yangklang P. 2004. A third way to travel: The place of Thai and serial verb languages in motion event typology. - Strömqvist S., Verhoeven L. (eds.). Relating events in narrative: Typological and contextual perspectives. Mahwah (NJ): Lawrence Erlbaum Associate: 159-190. 